\title{
CARTILAGE TISSUE ENGINEERING USING PRE-AGGREGATED HUMAN ARTICULAR CHONDROCYTES
}

\author{
F. Wolf ${ }^{\S}$, C. Candrian ${ }^{\S}$ D. Wendt, J. Farhadi, M. Heberer, I. Martin* and A. Barbero \\ Departments of Surgery and of Biomedicine, University Hospital, Basel, Switzerland \\ ${ }^{\S}$ Both authors contributed equally
}

\begin{abstract}
In this study, we first aimed at determining whether human articular chondrocytes (HAC) proliferate in aggregates in the presence of strong chondrocyte mitogens. We then investigated if the aggregated cells have an enhanced chondrogenic capacity as compared to cells cultured in monolayer. HAC from four donors were cultured in tissue culture dishes either untreated or coated with $1 \%$ agarose in the presence of TGF $\beta-1$, FGF-2 and PDGF-BB. Proliferation and stage of differentiation were assessed by measuring respectively DNA contents and type II collagen mRNA. Expanded cells were induced to differentiate in pellets or in Hyaff ${ }^{\circledR}-11$ meshes and the formed tissues were analysed biochemically for glycosaminoglycans (GAG) and DNA, and histologically by Safranin O staining. The amount of DNA in aggregate cultures increased significantly from day 2 to day 6 (by 3.2 -fold), but did not further increase with additional culture time. Expression of type II collagen mRNA was about two orders of magnitude higher in aggregated HAC as compared to monolayer expanded cells. Pellets generated by aggregated HAC were generally more intensely stained for GAG than those generated by monolayer-expanded cells. Scaffolds seeded with aggregates accumulated more GAG (1.3-fold) than scaffolds seeded with monolayer expanded HAC. In conclusion, this study showed that HAC culture in aggregates does not support a relevant degree of expansion. However, aggregation of expanded HAC prior to loading into a porous scaffold enhances the quality of the resulting tissues and could thus be introduced as an intermediate culture phase in the manufacture of engineered cartilage grafts.
\end{abstract}

Keywords: articular chondrocytes, chondrogenesis, cell differentiation, cartilage tissue engineering.

*Address for correspondence:

Ivan Martin

Institute for Surgical Research and Hospital Management University Hospital Basel

Hebelstrasse 20, ZLF, Room 405

CH-4031 Basel, Switzerland

Telephone Number: + 41612652384

FAX Number: + 41612653990

E-mail: imartin@uhbs.ch
Introduction

Cartilage repair techniques based on the use of autologous chondrocytes, either directly injected into the defect or further processed to engineer cartilaginous grafts, typically rely on the ex vivo expansion of the limited number of cells that can be obtained from a small biopsy. However, chondrocyte expansion is intrinsically associated with the well-known problem of cell de-differentiation (Benya and Shaffer, 1982; Binette et al., 1998), and the redifferentiation capacity of expanded cells, especially if of human origin, is rather limited (Bonaventure et al., 1994). In order to enhance the chondrogenic ability of expanded chondrocytes, several strategies have been proposed with various degrees of success, including medium supplementation with specific growth factors (Jakob et al., 2001; Barbero et al., 2003; Malpeli et al., 2004), cell growth on microcarrier beads (Malda et al., 2003) or on collagen type II-coated substrates (Barbero et al., 2006).

Alternatively, considering that chondrocyte dedifferentiation is linked to the cytoskeletal changes induced by cell spreading on a culture substrate (Mayne et al., 1976), chondrocytes could be expanded under conditions inhibiting cell adhesion. The proof of principle of this approach was provided by chondrocyte expansion in alginate beads (Lee et al., 2003); however, repeated passaging in alginate was necessary to obtain relevant numbers of cells. A more simple implementation of the same principle would be offered by chondrocyte culture on agarose coated dishes. Using this culture model, human articular chondrocytes (HAC) have been shown to form three-dimensional (3D) aggregates, also referred to as clusters or spheroids, and to maintain the expression of cartilage specific proteins (Kolettas et al., 1995; Anderer and Libera, 2002). However, little or no proliferation was reported (Kolettas et al., 1995).

In this study, we first aimed at determining whether in the presence of a combination of strong chondrocyte mitogens it is possible to achieve HAC proliferation in aggregate cultures. We then investigated whether the aggregated cells have an enhanced chondrogenic capacity as compared to cells cultured using traditional monolayer techniques. A partial expansion in monolayer prior to the culture phase in aggregate was introduced to permit more extensive cell proliferation while minimizing chondrocyte de-differentiation (Fig. 1). The chondrogenic ability of the expanded cells was then tested in a standard pellet culture model or using a porous 3D scaffold, that would permit the generation of relatively large cartilage grafts with a limited amount of chondrocyte aggregates. 


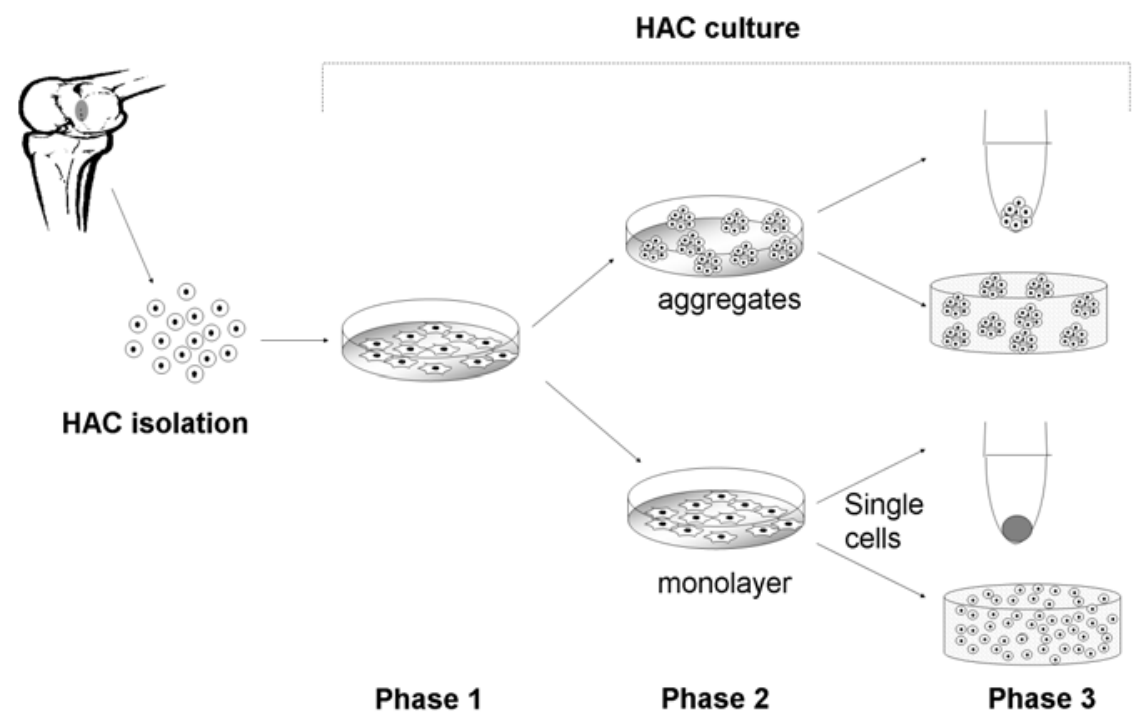

Figure 1. Experimental design. Human articular chondrocytes (HAC) isolated from cartilage biopsies $(N=4)$ were expanded for one passage in monolayer (Phase 1) and then cultured in dishes either uncoated or coated with agarose to generate monolayer cells or form aggregates, respectively (Phase 2). At the end of Phase 2, aggregates or monolayer expanded chondrocytes were induced to redifferentiate in a pellet culture model or within Hyaff ${ }^{\mathbb{B}}-11$ non-woven meshes (Phase 3).

\section{Materials and Methods}

\section{Cartilage collection and cell isolation}

Human articular cartilage samples (approximately $200 \mathrm{mg}$ tissue) were collected after informed consent and in accordance with the local Ethical Commission from the knee joints of 4 individuals with no known clinical history of joint disorders (donor 1: female, 51 years; donor 2: female, 67 years; donor 3: male, 71 years, donor 4: male, 18 years). Chondrocytes were isolated using $0.15 \%$ type II collagenase (Bioconcept Worthington, Allschwill, Switzerland) for 22 hours and resuspended in Dulbecco's modified Eagle's medium (DMEM) containing, $4.5 \mathrm{mg} /$ $\mathrm{ml}$ D-glucose, $0.1 \mathrm{mM}$ nonessential amino acids, $1 \mathrm{mM}$ sodium pyruvate, $100 \mathrm{mM}$ HEPES buffer, $100 \mathrm{U} / \mathrm{ml}$ penicillin, $100 \mu \mathrm{g} / \mathrm{ml}$ streptomycin, $0.29 \mathrm{mg} / \mathrm{ml} \mathrm{L}$ glutamine (complete medium) and 10\% foetal bovine serum (FBS).

\section{Cell expansion and aggregation}

Human articular chondrocytes (HAC) were plated on tissue culture dishes at $10^{4}$ cells $/ \mathrm{cm}^{2}$ in $10 \%$ FBS supplemented complete medium with the addition of $5 \mathrm{ng} / \mathrm{ml}$ of Fibroblast Growth Factor-2, $10 \mathrm{ng} / \mathrm{ml}$ of Platelet-Derived Growth Factor-bb and $1 \mathrm{ng} / \mathrm{ml}$ of Transforming Growth Factor- $\beta 1$ (all from R\&D Systems, Minneapolis, MN, USA), previously reported to be potent mitogens for HAC (Jakob et al., 2001), and cultured until they reached about $80 \%$ confluence (7-10 days; Phase 1, see Fig.1). HAC were then detached using $0.3 \%$ type II collagenase and $0.05 \%$ trypsin/0.53mM EDTA (Gibco; Invitrogen, Basel, Switzerland) and replated at $5 \times 10^{3}$ cells $/ \mathrm{cm}^{2}$ in culture dishes either untreated or coated with $1.0 \%$ agarose (Sigma-Aldrich, Hamburg, Germany), in order to support respectively cell growth in monolayers or the formation of aggregates (up to 14 days; Phase 2, see Fig.1). Culture medium during Phase 2 was also supplemented with the 3 growth factors used for Phase 1. At each feeding, aggregates collected in the spent medium were resuspended in fresh medium and returned to the culture dish. Cells cultured in monolayer or in aggregates were either processed for gene expression analysis or induced to redifferentiate using the two models described below (Phase 3, see Fig. 1).

\section{Cell redifferentiation}

Pellet culture. For this differentiation assay, cells from 3 donors (donor 1, donor 2 and donor 3) were used. Monolayer- or aggregate-cultured cells were transferred into polypropylene conical tubes (respectively $5 \times 10^{5}$ cells/ pellet and 1 to 4 aggregates/pellet, depending on their size) in the presence of complete medium supplemented with insulin, transferrin and selenous acid $\left(\mathrm{ITS}^{+1}\right.$, Sigma Chemical, St. Louis, MO, USA), $0.1 \mathrm{mM}$ ascorbic acid 2phosphate, $1.25 \mathrm{mg} / \mathrm{ml}$ human serum albumin, $10^{-7} \mathrm{M}$ dexamethasone and $10 \mathrm{ng} / \mathrm{ml}$ Transforming Growth Factor- $\beta 1$ to establish pellet cultures, as previously described (Barbero et al., 2004). Pellets were placed onto a 3D orbital shaker (Bioblock Scientific, Frenkendorf, Switzerland) at $30 \mathrm{rpm}$ and cultured for 2 weeks in $0.5 \mathrm{ml}$ of medium/pellet, with medium changes twice per week. Subsequently pellets were processed for histological or biochemical analysis.

3D culture within scaffolds. For this differentiation assay, cells from 2 donors (donor 3 and donor 4) were used. Monolayer- or aggregate-cultured cells were seeded on Hyaff $^{\circledR}-11$ non-woven meshes $(8 \mathrm{~mm}$ diameter, $2 \mathrm{~mm}$ thick discs; Fidia Advanced Biopolymers, Abano Terme, Italy) by direct perfusion through the scaffold pores. 4 or 8 millions of HAC as single cells or as aggregates were 
perfused in alternate directions through each mesh in $4 \mathrm{ml}$ of culture medium at a superficial velocity of $3 \mathrm{ml} / \mathrm{min}$ for 24 hours (Wendt et al., 2003). The number of cells in aggregates was estimated by measuring the DNA contents of aliquots of cell-cluster suspension on the day before the seeding. After perfusion seeding the resulting cell-scaffold constructs were processed histologically to examine the distribution of the cells thought the scaffold, by quantifying the DNA content to assess the cell seeding efficiency, or transferred on agarose coated dishes and cultured in complete medium supplemented with 10\% FBS, $0.1 \mathrm{mM}$ ascorbic acid 2-phosphate, $10 \mathrm{mg} / \mathrm{ml}$ Insulin and $10 \mathrm{ng} / \mathrm{ml}$ Transforming Growth Factor-b3 for 4 weeks with medium changes twice per week (Candrian et al., 2008).

\section{Analyses of cells and tissues}

Real-time quantitative RT-PCR assays. Total RNA of cells after Phase 2 (see Fig. 1) was extracted using Trizol (Life Technologies, Basel, Switzerland) and the standard single-step acid-phenol guanidinium method. RNA was treated with DNAseI using the DNA-free ${ }^{\mathrm{TM}}$ Kit (Ambion/ Applied Biosystems, Foster City, CA, USA) and quantified spectrometrically. cDNA was generated from $3 \mu \mathrm{g}$ of RNA by using $500 \mu \mathrm{g} / \mathrm{ml}$ random hexamers (Catalys AG, Wallisellen, Switzerland) and $1 \mu \mathrm{l}$ of $50 \mathrm{U} / \mathrm{ml}$ Stratascript ${ }^{\mathrm{TM}}$ reverse transcriptase (Stratagene, Amsterdam, the Netherlands), in the presence of dNTPs. Real-time RT-PCR reactions were performed and monitored using the ABI Prism 7700 Sequence Detection System (Perkin-Elmer/ Applied Biosystems, Rotkreuz, Switzerland). After an initial denaturation at $95^{\circ} \mathrm{C}$ for $10 \mathrm{~min}$, the cDNA products were amplified with 45 PCR cycles, consisting of a denaturation step at $95^{\circ} \mathrm{C}$ for $15 \mathrm{~s}$ and an extension step at $60^{\circ} \mathrm{C}$ for $1 \mathrm{~min}$. The following primers and probes were used at the concentrations indicated in parenthesis:

\section{CII-forward primer:}

5'-GGCAATAGCAGGTTCACGTACA (900 nM),

CII-reverse primer:

5'-CGATAACAGTCTTGCCCCACTT (900 nM), CII-probe:

5'-CCGGTATGTTTCGTGCAGCCATCCT (200 nM);

18-S-forward primer:

5'-CGGCTACCACATCCAAGGAA (26 nM),

18-S-reverse primer:

5'-GCTGGAATTACCGCGGCT (26 nM), 18-S-probe:

5'-TGCTGGCACCAGACTTGCCCTC (50 nM).

For each sample, the threshold cycle $(\mathrm{Ct})$ value was determined as the cycle number at which the fluorescence intensity reached 0.05 . For each cDNA sample, the value of 18-S was subtracted from the Ct value of the target gene, to derive $\mu \mathrm{Ct}$. The level of expression of type II collagen was calculated as $2^{\mu \mathrm{Ct}}$. Each sample was assessed at least in duplicate.

DNA and Glycosaminoglycan (GAG) quantification. Aggregates generated at different times during Phase 2 (i.e., at day 0, 2, 4, 6, 8 and 14), pellets cultured for 2 weeks and cell-scaffold constructs immediately after seeding or 4 weeks's culture were digested with protease $\mathrm{K}(0.5 \mathrm{ml}$ of $1 \mathrm{mg} / \mathrm{ml}$ protease $\mathrm{K}$ in $50 \mathrm{mM}$ Tris with $1 \mathrm{mM}$ EDTA, $1 \mathrm{mM}$ iodoacetamide, and
$10 \mu \mathrm{g} / \mathrm{ml}$ pepstatin-A for 15 hours at $56^{\circ} \mathrm{C}$ ) as previously described (Hollander et al., 1994). The DNA amount was measured spectrofluorometrically using the CyQUANT ${ }^{\circledR}$ Kit (Molecular Probes, Eugene, OR, USA) following the kit's instruction. Briefly, CyQUANT® NF dye reagent was applied to cell lysets aliquoted in a 96-well plate (3 wells per sample). After a 30 minute incubation, fluorescence was measured (excitation: $485 \mathrm{~nm}$; emission: $530 \mathrm{~nm}$ ) and compared to standard curve prepared simultaneously using calf thymus DNA.

Glycosaminoglycan (GAG) contents of pellets and constructs were measured spectrophotometrically using the dimethylmethylene blue (DMMB) assay (Farndale et al., 1986). Briefly, DMMB solution was applied to cell lysets aliquoted in a 96-well plate (4 wells per sample). Absorbance was measured at $525 \mathrm{~nm}$ and compared to curve prepared simultaneously using chondroitin sulphate (Sigma-Aldrich). GAG contents of pellets and cell-scaffold constructs are reported as $\mu \mathrm{g}$ GAG / $\mu \mathrm{g}$ DNA.

Histological analysis. Cell pellets and cell-scaffold constructs were fixed in $4 \%$ formalin, embedded in paraffin, cross-sectioned ( $5 \mu \mathrm{m}$ thick) and stained with Safranin O for sulphated GAG.

Statistical Analysis. All values are presented as mean \pm standard deviation of measurements from 3 independent experiments (i.e., with cells from the 3 different donors). Differences among experimental groups were assessed by Mann Whitney tests, and considered statistically significant with $\mathrm{P}<0.05$.

\section{Results and Discussion}

\section{Proliferation and differentiation stage of HAC cultured in monolayer or in aggregates}

In the first set of experiments HAC were cultured in monolayer or on agarose coated dish in the presence of a growth factor combination (namely TGF $\beta-1$, FGF-2 and PDGF-BB) known to strongly enhance the proliferation rate of monolayer cultured chondrocytes (Barbero et al., 2003). HAC cultured on agarose coated surfaces remained non-adherent and formed aggregates growing in size with time, in agreement with previous studies (Archer et al., 1990; Izumi et al., 2000; Kolettas et al., 1995; Anderer and Libera, 2002). In particular, during the first 6 days of aggregate culture cells generated rather uniformly sized aggregates (size 15-70 $\mu \mathrm{m}$ ), which during the second week of expansion tended to fuse together and form larger aggregates, with highly variable sizes (Fig. 2A). The amount of DNA in aggregate cultures increased significantly from day 2 to day 6 (by 3.2 -fold), but did not further increase with additional culture time (Fig. 2B). During the first 6 days of culture in Phase 2, as compared to monolayer-expanded cells, the proliferation rate of HAC cultured in aggregates was 5.4-fold lower (Fig. 2C), whereas the expression of collagen type II mRNA was about two orders of magnitude higher (Fig. 2D), and only about 5-fold lower than in native cartilage tissues. Our findings are in general agreement with those by Kolettas et al. (1995), reporting that chondrocytes in aggregates 
A
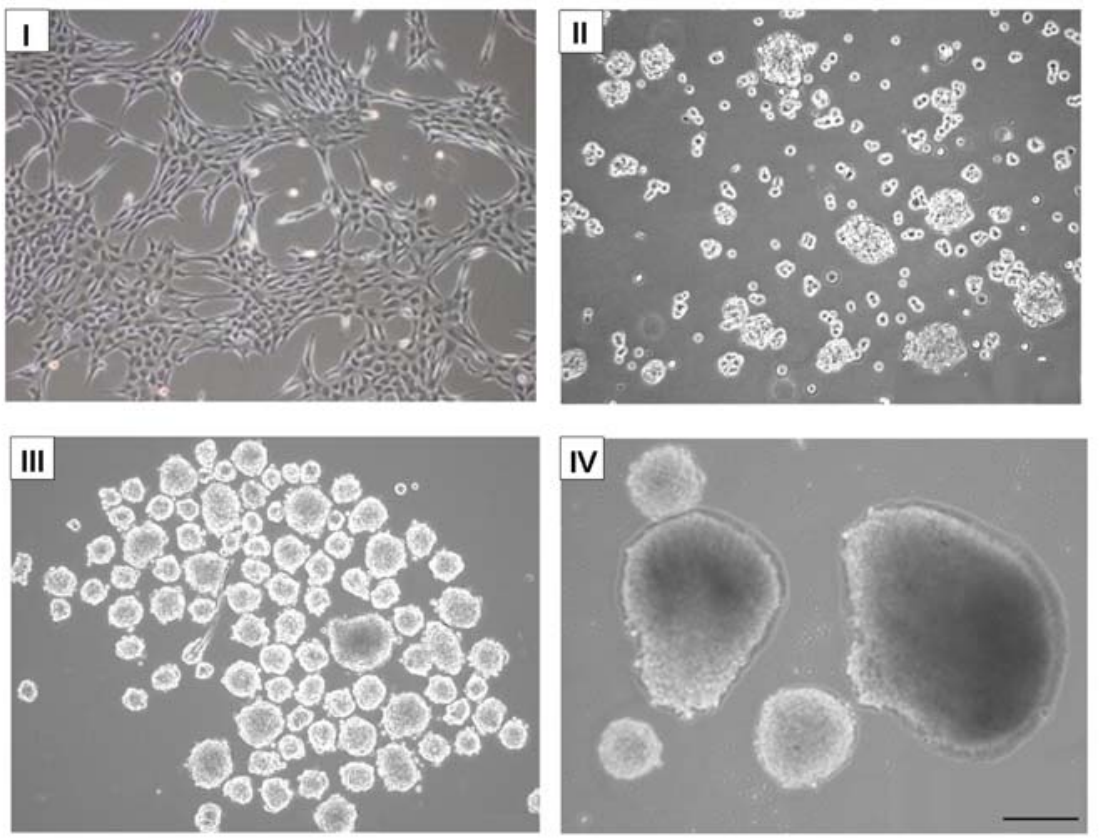

B

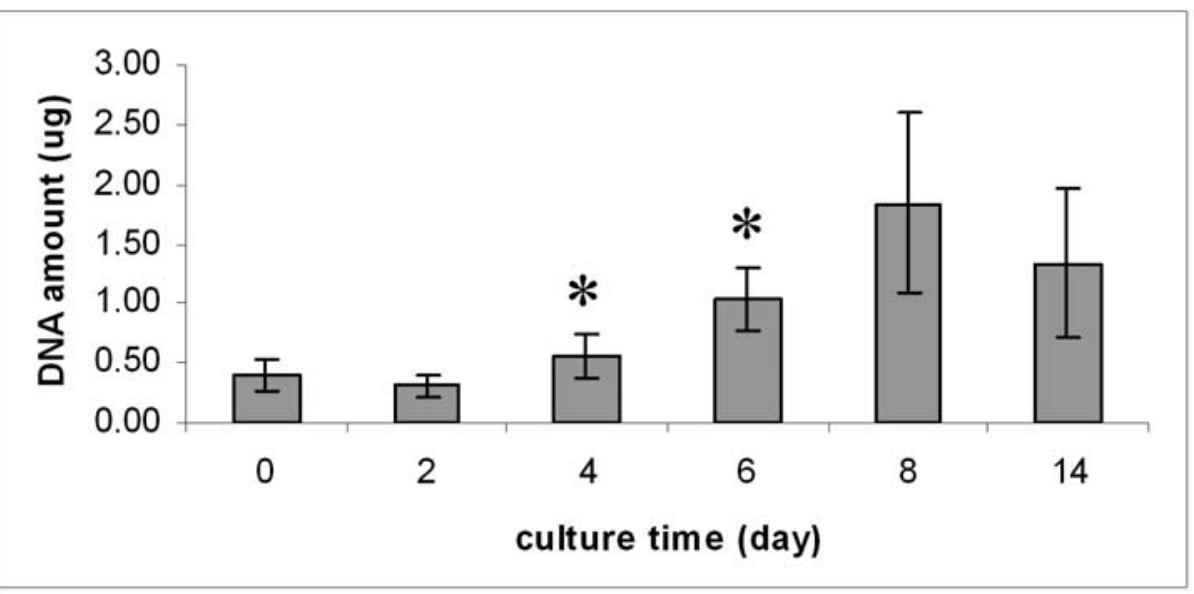

C

D
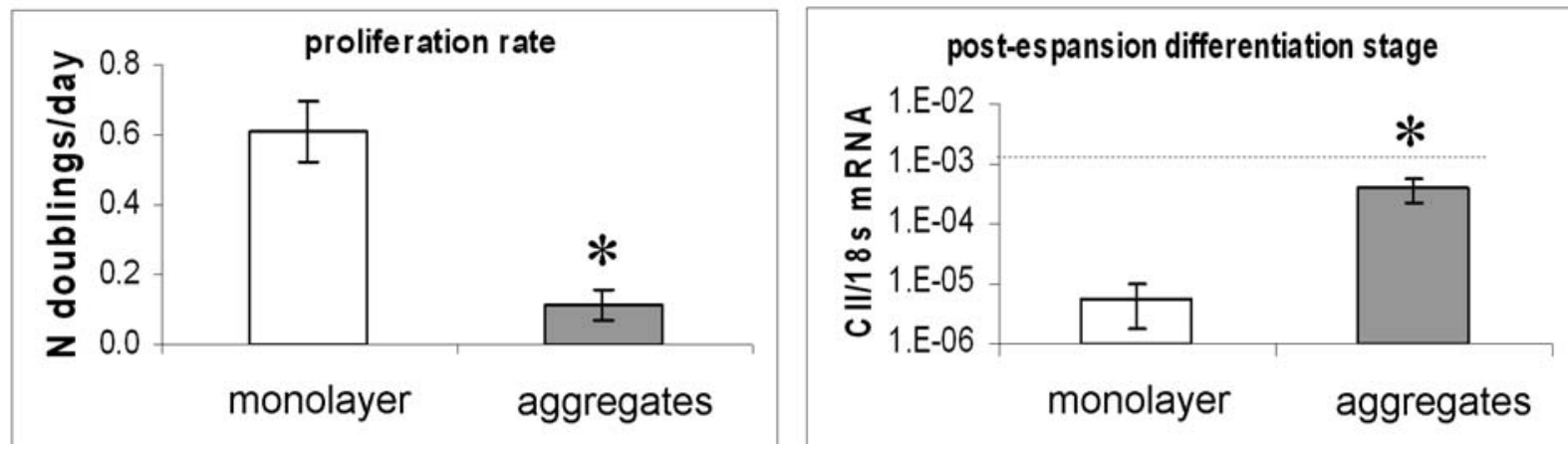

Figure 2. Morphology, proliferation capacity and phenotype of human articular chondrocytes (HAC) expanded in monolayer or aggregates. (A) Representative pictures of monolayer (I) and aggregates (II, III and IV) formed by HAC at day 3 (II), 6 (I and III), or 14 (IV) of culture in Phase 2. Bar $=100 \mu \mathrm{m}$. (B) DNA quantification of HAC cultured as aggregates for different time points. ${ }^{*}=\mathrm{p}<0.05$ from the previous time point. (C) Proliferation rates of HAC expanded as monolayer or aggregates. $*=p<0.05$ from monolayer. (D) Real time RT-PCR analysis of the mRNA expression of collagen type II by HAC after 6 days of culture in Phase 2. The dashed line indicates the mean collagen type II mRNA expression level of corresponding native tissues. $*=$ $\mathrm{p}<0.05$ from monolayer. 
A

Single cells

Aggregates
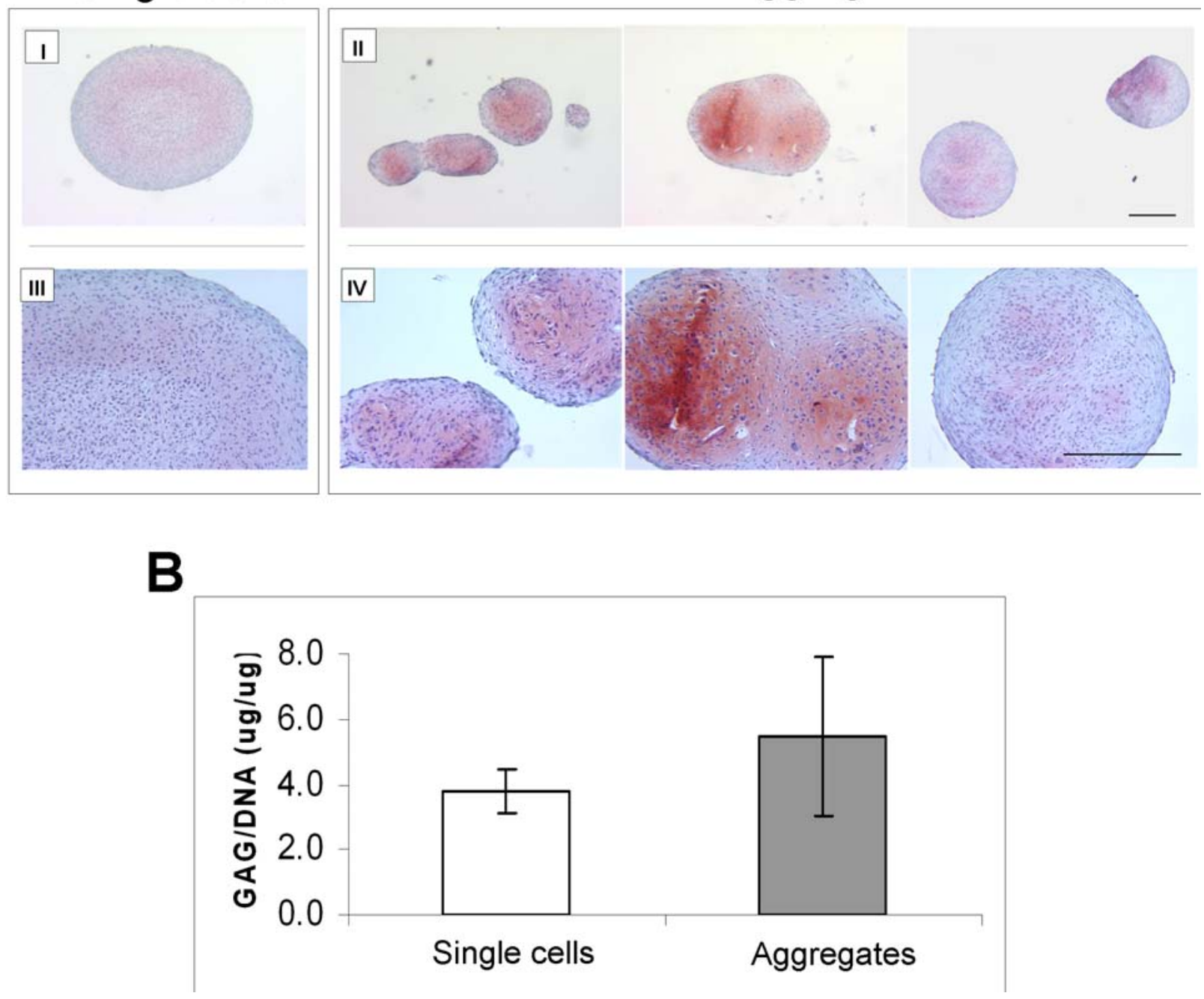

Figure 3. Redifferentiation of human articular chondrocytes (HAC) cultured as monolayer or aggregates in pellets. (A) Safranin O staining of representative pellets generated by HAC cultured as monolayer (I and III) or aggregates (II and IV) after two weeks' culture in chondrogenic medium. Bars $=100 \mu \mathrm{m}$. (B) Sulphated glycosaminoglycan (GAG) content, normalized to the DNA content, of the pellets generated by HAC expanded as monolayer or aggregates after two weeks' culture in chondrogenic medium.

expressed higher amounts of collagen type II both at mRNA and protein level than those cultured in monolayer. The limited proliferative activity of chondrocytes in aggregates, despite the medium supplementation with potent mitogens, is also consistent with previous reports on disc cells, which were found to weakly respond to the mitogenic factor PDGF when cultured in alginate (Gruber and Hanley, 2000).

Since aggregate culture did not result in relevant proliferation (i.e., only about 1 doubling in the first 6 days), for subsequent experiments of tissue formation (Phase 3) we compared cells cultured as monolayer or as aggregates in Phase 2 only for 3 days. Thus, for these experiments aggregation in Phase 2 was not used to further expand cells, but only to pre-condition cells for subsequent chondrogenesis assays.

\section{Redifferentiation of HAC cultured in monolayer or in aggregates}

Pellet culture. HAC from three donors cultured in monolayer or aggregates for 3 days in Phase 2 were transferred into a pellet culture model and induced to redifferentiate in the presence of chondrogenic stimuli. After 2 weeks' culture, pellets generated by aggregated HAC were generally more intensely stained for GAG than those generated by monolayer-expanded cells isolated from the same donors, although variable levels of GAG staining intensity were observed in pellets derived by different aggregates from the same primary culture (Fig 3A). Thus, no statistically significant difference in the biochemically determined GAG/DNA could be established (Fig. 3B). The variations observed among aggregates might be due to the fact that they were formed by distinct sub-populations of chondrocytes present within native cartilage (Barbero et 


\section{donor 3}

A Single cells

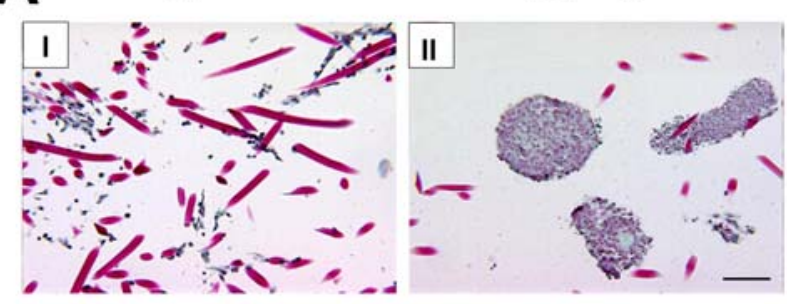

C Single cells

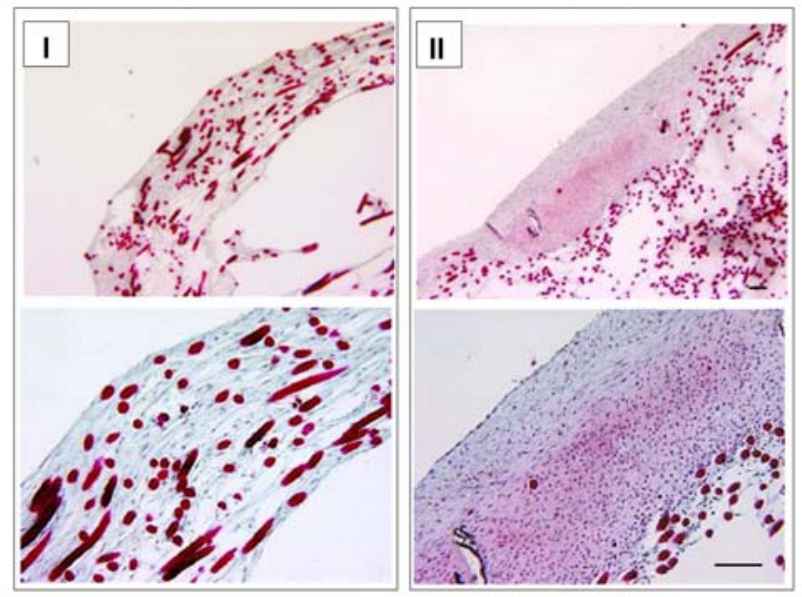

E

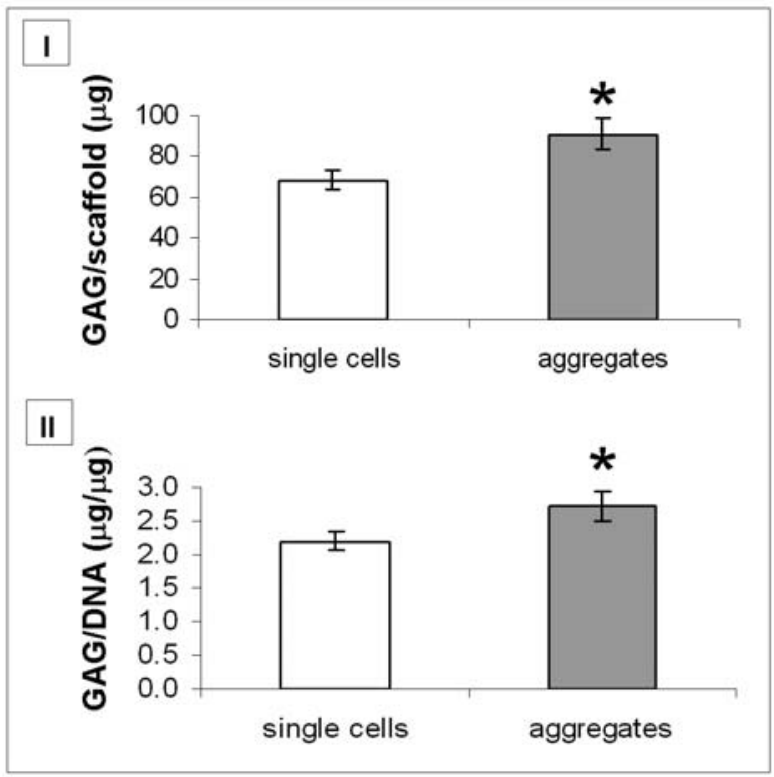

donor 4

B Single cells

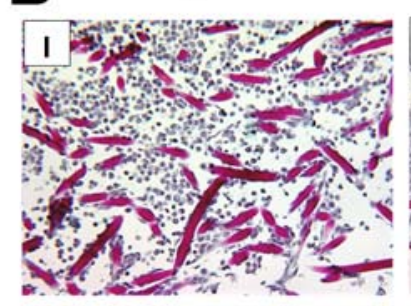

Aggregates

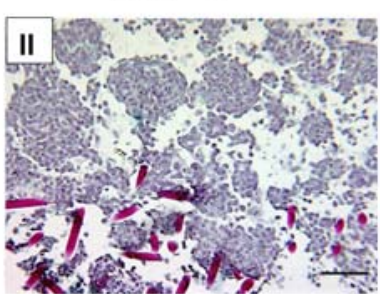

D Single cells

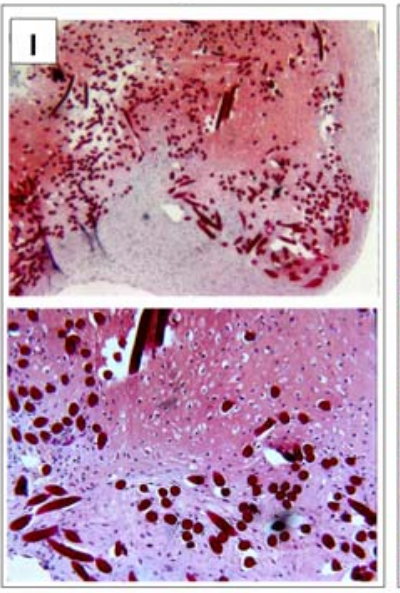

Aggregates

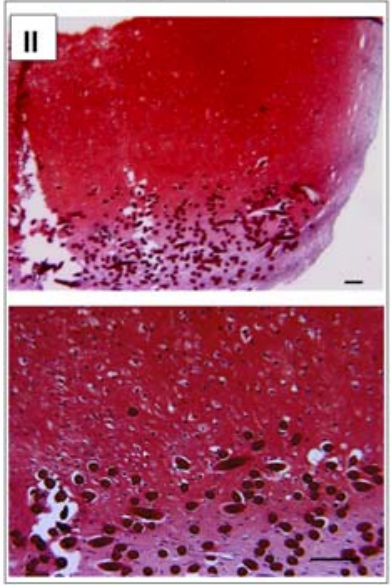

F

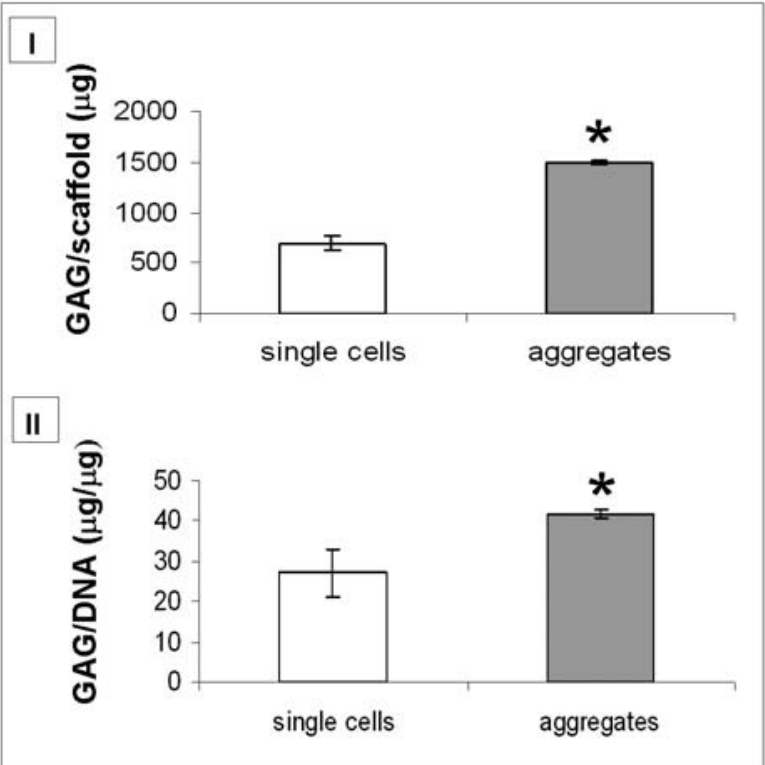

Figure 4. Redifferentiation of human articular chondrocytes (HAC) derived from donor 3 (71 y) or donor 4 (18 y) seeded as monolayer or aggregates within a scaffold. (A-B) Distribution of HAC thought the Hyaff ${ }^{\circledR}-11$ non-woven meshes following 24 hours perfusion seeding of cells cultured as monolayer (I) or aggregates (II). (CD) Safranin O staining of representative constructs generated by HAC cultured as monolayer (I) or aggregates (II) after two weeks' culture in chondrogenic medium. Bars $=100 \mu \mathrm{m}$. (E-F) Sulphated glycosaminoglycan (GAG) content of the resulting tissues, reported as total amounts / scaffold (I) or after normalization to the DNA content (II). 
al., 2003; Thornemo et al., 2005), or that they were at different stages of development upon transfer into pellets. Alternatively, since the number of chondrocytes per aggregate could not be controlled, the variability in the chondrogenesis among aggregates might have resulted from differences in their size, in turn affecting patterns of nutrition and/or generation of oxygen gradients.

3D culture within scaffolds. HAC from donor 3 (71 years) were cultured in monolayer or aggregates for 3 days in Phase 2 and then seeded within Hyaff ${ }^{\circledR}-11$ meshes under direct perfusion at a density of 4 millions of cells per scaffold. The efficiency of seeding of both monolayer- or aggregate-cultured chondrocytes, calculated by assessing the DNA content of seeded constructs, was consistently greater than $90 \%$. After 4 weeks' culture in chondrogenic medium, cells expanded in monolayer remained fibroblastic and the resulting tissues were only faintly stained for GAG (Fig. 4C). In contrast, HAC cultured in aggregates for 3 days had a more round morphology and generated scattered areas of Safranin O-positive matrix. Biochemical analyses confirmed a significantly higher accumulation of GAG in scaffolds seeded with aggregateas compared to monolayer-cultured cells (Fig. 4E). The overall limited extent of chondrogenesis, under similar conditions previously reported to support cartilage tissue formation, can be explained by the rather old age of the donor (Barbero et al., 2004) and/or the low cell seeding density used (Moretti et al., 2005) (Fig 4A). We thus performed one additional experiment in which cells derived from a younger donor (donor 4, 18 years) were seeded at higher density in the scaffold (i.e.: 8 millions cells/scaffold) as single cells (i.e.: cells cultured in monolayer) or aggregates. Histological analysis of scaffolds after 24 hours perfusion seeding confirmed that scaffolds seeded with HAC from donor 4 were more cellular than those seeded with HAC from donor 3 and indicated that, while single cells were uniformly distributed through the scaffolds, aggregates were mainly concentrated at the periphery (Fig 4A-B). Despite the generally higher extent of chondrogenesis by cells from donor 4 in each culture condition, the trend of improved deposition of GAG following pre-aggregation was confirmed (Fig. 4D and F). Enhancement of chondrogenesis following cell aggregation may be explained by early upregulation of cell-cell and cell-matrix adhesion molecules, which are known to be key to initiate the chondrocyte differentiation program during mesenchymal condensation (Tavella et al., 1997). This interpretation would be consistent with a less marked effect of HAC aggregation in the pellet culture model, where the high cell density would already induce upregulation of such molecules (DeLise et al., 2000). The results are also consistent with the findings of Masuda et al. (2003) that a first step of chondrocyte culture in alginate induces the production of a proteoglycan-rich cell associated matrix (CM) and the formation of cartilaginous structures following culture of the recovered cells and CM from the beads within a porous membrane. Preferential chondrogenesis at the periphery of the aggregate-seeded scaffolds could be explained by an initially higher cell density in the outer region of the constructs, which in turn could result from a limited penetration of the aggregates through the scaffold pores during seeding, and/or from limited nutrition of cells in the interior regions. A higher uniformity of the engineered cartilage grafts could thus be obtained by (i) standardizing the size and shape of the aggregates into a suitable range (e.g., by using hanging drop methods (Kelm et al., 2003; Del Duca et al., 2004)), (ii) using scaffolds with a more open pore structure (e.g., rapid-prototyped structures with grid shapes (Woodfield et al., 2004)), and/or (iii) increasing mass transport through the constructs (e.g., continuing the perfusion regime following cell seeding (Wendt et al., 2006)).

\section{Conclusions}

We have shown that even in the presence of strong chondrocyte mitogens, HAC in aggregate cultures undergo a limited extent of growth, but their dedifferentiation is strongly reduced as compared to cells expanded in monolayer for the same time. Aggregation of HAC prior to perfusion-seeding into porous scaffolds enhanced chondrogenesis and allowed generation of cartilage tissues with increased GAG contents. Our study provides a proofof-principle that HAC expansion in monolayer combined with a subsequent short culture phase in aggregate prior to seeding into a scaffold could be a valid strategy to engineer cartilage grafts starting from the limited number of cells that can be isolated from a small biopsy.

\section{Acknowledgements}

Hyaff $^{\circledR}-11$ was kindly provided by Fidia Advanced Biopolymer, Abano Terme, Italy.

\section{References}

Anderer U, Libera J (2002) In vitro engineering of human autogenous cartilage. J Bone Miner Res 17: 1420 1429.

Archer CW, McDowell J, Bayliss MT, Stephens MD, Bentley G (1990) Phenotypic modulation in subpopulations of human articular chondrocytes in vitro. J Cell Sci 97: 361-371.

Barbero A, Ploegert S, Heberer M, Martin I (2003) Plasticity of clonal populations of dedifferentiated adult human articular chondrocytes. Arthritis Rheum 48: 13151325.

Barbero A, Grogan S, Schafer D, Heberer M, MainilVarlet P, Martin I (2004) Age related changes in human articular chondrocyte yield, proliferation and postexpansion chondrogenic capacity. Osteoarthritis Cartilage 12: 476-484.

Barbero A, Grogan SP, Mainil-Varlet P, Martin I (2006) Expansion on specific substrates regulates the phenotype and differentiation capacity of human articular chondrocytes. J Cell Biochem 98: 1140-1149.

Benya PD, Shaffer JD (1982) Dedifferentiated chondrocytes reexpress the differentiated collagen phenotype when cultured in agarose gels. Cell 30: 215224. 
Binette F, McQuaid DP, Haudenschild DR, Yaeger PC, McPherson JM, Tubo R (1998) Expression of a stable articular cartilage phenotype without evidence of hypertrophy by adult human articular chondrocytes in vitro. J Orthop Res 16: 207-216.

Bonaventure J, Kadhom N, Cohen-Solal L, Ng KH, Bourguignon J, Lasselin C, Freisinger P (1994) Reexpression of cartilage-specific genes by dedifferentiated human articular chondrocytes cultured in alginate beads. Exp Cell Res 212: 97-104.

Candrian C, Vonwil D, Barbero A, Bonacina E, Miot S, Farhadi J, Wirz D, Dickinson S, Hollander A, Jakob M, Li Z, Alini M, Heberer M, Martin I (2008) Engineered cartilage generated by nasal chondrocytes is responsive to physical forces resembling joint loading. Arthritis Rheum 58: 197-208.

Del Duca D, Werbowetski T, Del Maestro RF (2004) Spheroid preparation from hanging drops: characterization of a model of brain tumor invasion. J Neurooncol 67: 295 303.

DeLise AM, Fischer L, Tuan RS (2000) Cellular interactions and signaling in cartilage development. Osteoarthritis Cartilage 8: 309-334.

Farndale RW, Buttle DJ, Barrett AJ (1986) Improved quantitation and discrimination of sulphated glycosaminoglycans by use of dimethylmethylene blue. Biochim Biophys Acta 883: 173-177.

Gruber HE, Hanley EN (2000) Human disc cells in monolayer vs 3D culture: cell shape, division and matrix formation. BMC Musculoskelet Disord 1: 1-6.

Hollander AP, Heathfield TF, Webber C, Iwata Y, Bourne R, Rorabeck C, Poole AR (1994) Increased damage to type II collagen in osteoarthritic articular cartilage detected by a new immunoassay. J Clin Invest 93: 17221732 .

Izumi T, Tominaga T, Shida J, Onishi F, Itoman M (2000) Chondrocyte transplantation for osteochondral defects with the use of suspension culture. Cell Tissue Bank 1: 207-212.

Jakob M, Demarteau O, Schafer D, Hintermann B, Dick W, Heberer M, Martin I (2001) Specific growth factors during the expansion and redifferentiation of adult human articular chondrocytes enhance chondrogenesis and cartilaginous tissue formation in vitro. J Cell Biochem 81: 368-377.

Kelm JM, Timmins NE, Brown CJ, Fussenegger M, Nielsen LK (2003) Method for generation of homogeneous multicellular tumor spheroids applicable to a wide variety of cell types. Biotechnol Bioeng 83: 173-180.

Kolettas E, Buluwela L, Bayliss MT, Muir HI (1995) Expression of cartilage-specific molecules is retained on long-term culture of human articular chondrocytes. J Cell Sci 108: 1991-1999.

Lee DA, Reisler T, Bader DL (2003) Expansion of chondrocytes for tissue engineering in alginate beads enhances chondrocytic phenotype compared to conventional monolayer techniques. Acta Orthop Scand 74: 6-15.

Malda J, Kreijveld E, Temenoff JS, van Blitterswijk CA, Riesle J (2003) Expansion of human nasal chondrocytes on macroporous microcarriers enhances redifferentiation. Biomaterials 24: 5153-5161.

Malpeli M, Randazzo N, Cancedda R, Dozin B (2004) Serum-free growth medium sustains commitment of human articular chondrocyte through maintenance of Sox 9 expression. Tissue Eng 10: 145-155.

Masuda K, Sah RL, Hejna MJ, Thonar EJ (2003) A novel two-step method for the formation of tissueengineered cartilage by mature bovine chondrocytes: the alginate-recovered-chondrocyte (ARC) method. J Orthop Res 21: 139-148.

Mayne R, Vail MS, Mayne PM, Miller EJ (1976) Changes in type of collagen synthesized as clones of chick chondrocytes grow and eventually lose division capacity. Proc Natl Acad Sci USA 73: 1674-1678.

Moretti M, Wendt D, Dickinson SC, Sims TJ, Hollander AP, Kelly DJ, Prendergast PJ, Heberer M, Martin I (2005) Effects of in vitro preculture on in vivo development of human engineered cartilage in an ectopic model. Tissue Eng 11: 1421-1428.

Tavella S, Bellese G, Castagnola P, Martin I, Piccini D, Doliana R, Colombatti A, Cancedda R, Tacchetti C (1997) Regulated expression of fibronectin, laminin and related integrin receptors during the early chondrocyte differentiation. J Cell Sci 110: 2261-2270.

Thornemo M, Tallheden T, Sjogren JE, Larsson A, Lovstedt K, Nannmark U, Brittberg M, Lindahl A (2005) Clonal populations of chondrocytes with progenitor properties identified within human articular cartilage. Cells Tissues Organs 180: 141-150.

Wendt D, Marsano A, Jakob M, Heberer M, Martin I (2003) Oscillating perfusion of cell suspensions through three-dimensional scaffolds enhances cell seeding efficiency and uniformity. Biotechnol Bioeng 84: 205-214.

Wendt D, Stroebel S, Jakob M, John GT, Martin I (2006) Uniform tissues engineered by seeding and culturing cells in 3D scaffolds under perfusion at defined oxygen tensions. Biorheology 43: 481-488.

Woodfield TB, Malda J, de Wijn J, Peters F, Riesle J, van Blitterswijk CA (2004) Design of porous scaffolds for cartilage tissue engineering using a three-dimensional fiber-deposition technique. Biomaterials 25: 4149-4161. 